ISSN 0258-7122

Bangladesh J. Agril. Res. 36(3) : 513-519, September 2011

\title{
CHANGES IN DIFFERENT FORMS OF K IN RICE RHIZOSPHERE UNDER K APPLICATION
}

\author{
M. S. UDDIN ${ }^{1}$, M. J. ABEDIN MIAN ${ }^{2}$, M. R. ISLAM ${ }^{3}$ \\ M. A. SALEQUE ${ }^{4}$ AND A. Z. M. MOSLEHUDDiN ${ }^{5}$
}

\begin{abstract}
A pot experiment was conducted with four soils from two locations (BAU farm, Mymensingh and BADC farm, Madhupur, Tangail) in order to monitor the transformation of added $\mathrm{K}$ (soil solution $\mathrm{K}$, exchangeable $\mathrm{K}^{+}$and nonexchangeable $\mathrm{K}$ ) in BRRI dhan-41 rhizosphere at saturation condition. There were six levels of K viz., 0, 30, 60, 90,120 \& $150 \mathrm{~kg} / \mathrm{ha}$ from MoP. Eight kg soil was taken into each pot. The $\mathrm{K}$ concentration in soil solution increased with increasing $\mathrm{K}$ addition and decreased with increasing incubation period. Soil solution $\mathrm{K}$ was drastically reduced at 45 days due to higher crop uptake. The amount of exchangeable $\mathrm{K}$ also increased with increment of added $\mathrm{K}$ and gradually decreased over time. The non-exchangeable $\mathrm{K}$ increased up to 45 days and then decreased up to 105 days.
\end{abstract}

Keywords: Rice rhizosphere, exchangeable $\mathrm{K}^{+}$, non-exchangeable $\mathrm{K}$.

\section{Introduction}

The positively charged $\mathrm{K}$ ions that are held at the edges of the clay layers and towards the outer edge of any interlayer space can be replaced easily by other cations. Quantities of $\mathrm{K}$ released from clay and silt fractions were comparable and twice as high as from sand fractions. Interlayer $\mathrm{K}$ released from silt and clay fractions, is important for plant $\mathrm{K}$ nutrition and thus, it should be considered in $\mathrm{K}$ fertilizer management. The released $\mathrm{K}$ comes into the soil solution from where it is taken up by plant roots. Potassium in the most interior phase in the interlayer space can only be exchanged slowly. A reverse of the above process occurs when the concentration of $\mathrm{K}$ in the soil solution is increased due to the addition of fertilizers and manures. The release of $\mathrm{K}$ is governed by the composition and concentration of the soil solution (Beckett, 1964). As a result of the later process, a reserve of potassium is built up in soils.

Fortunately, some soils contain considerable amount of non-exchangeable but slowly available forms of this element. But the capacity of soils to supply nutrients is gradually declining over time due to intensive cropping with high yielding varieties. For this reason, farmers routinely apply sufficient K containing

${ }^{1}$ Assistant Professor, Dept. of Agriculture, Govt. V.M. College, Saturia, Manikgonj, ${ }^{2,3 \& 5}$ Professor, Dept. of Soil Science, Bangladesh Agricultural University (BAU), Mymensingh, ${ }^{4}$ Principal Scientific Officer, Soil Science Division, Bangladesh Agricultural Research Institute (BRRI), Joydebpur, Gazipur, Bangladesh. ${ }^{5}$ Professor, Dept. of Soil Science, BAU, Mymensingh. 
fertilizer to meet plant needs (Johnston, 1997). Therefore, the present work was designed to understand the $\mathrm{K}$ transformation in soil, namely soil solution $\mathrm{K}$, exchangeable $\mathrm{K}^{+}$and non-exchangeable $\mathrm{K}$ pools.

\section{Materials and Method}

An experiment was conducted with four soils (BAU-1, BAU-2, Madhupur-l, and Madhupur-2) from two locations (BAU farm, Mymensingh and BADC farm, Madhupur, Tangail) under net house condition at BAU, Mymensingh. The texture of soils was loam to silt loam. The $\mathrm{pH}$ of BADC farm soils was 4.83 to 5.22 and BAU farm soils 6.52 to 6.72 . The organic matter (0.77 to $0.87 \%)$ and exchangeable K $(0.087$ to $0.097 \mathrm{cmol} / \mathrm{kg})$ contents of BAU-l and Madhupur-1 soils were close to each other. The status of BAU-2 soil for both organic matter $(1.18 \%)$ and exchangeable $\mathrm{K}^{+}(0.146 \mathrm{cmol} / \mathrm{kg})$ was found higher compared to BAU-l and Madhupur-1 soils and lower than Madhupur-2 soil. The Madhupur-2 soil contained higher amount of organic matter $(1.29 \%)$ and exchangeable $\mathrm{K}^{+}$ $(0.706 \mathrm{cmol} / \mathrm{kg})$ compared to the other soils. The CEC of Madhupur-2 and BAU2 soils (12.58 and $12.51 \mathrm{cmol} / \mathrm{kg}$ ) were very close and higher than BAU-1 (11.12 $\mathrm{cmol} / \mathrm{kg}$ ) and Madhupur-1 $(9.50 \mathrm{cmol} / \mathrm{kg})$ soils. Calcium and $\mathrm{Mg}$ contents were higher in BAU farm soil (4 to $5.50 \mathrm{cmol} / \mathrm{kg}$ ) than in BADC farm soil (1.50 to $3.50 \mathrm{cmol} / \mathrm{kg}$ ). Mica was higher in BADC farm soil (33-35\%) while vermiculite was higher in BAU farm soil (14- 18\%) (Table 1).There was six levels of $\mathrm{K}$, such as $0,30,60,90,120$ and $150 \mathrm{~kg} / \mathrm{ha}$. Nitrogen, $\mathrm{P}$ and $\mathrm{S}$ were used as basal application. The doses were $67 \mathrm{~kg} \mathrm{~N} / \mathrm{ha}, 14 \mathrm{~kg}$ P/ha, and $5 \mathrm{~kg} \mathrm{~S} / \mathrm{ha}$ for BAU-1 soil, $54 \mathrm{~kg} \mathrm{~N} / \mathrm{ha}, 14 \mathrm{~kg} \mathrm{P} / \mathrm{ha}$, and $4 \mathrm{~kg} \mathrm{~S} / \mathrm{ha}$ for BAU-2 soil, $60 \mathrm{~kg} \mathrm{~N} / \mathrm{ha}$ for Madhupur-1 soil and $52 \mathrm{~kg}$ N/ha for Madhupur-2 soil. Phosphorus and S fertilizers were not applied in Madhupur-I and Madhupur-2 soils as their status was sufficient for rice cultivation. The experiment was designed in CRD with 3 replications. Eight kg soil was taken into each plastic plot. There were 72 plastic pots for this experiment. Soil and soil solution samples were collected from each pot at 15-day intervals up to crop harvest. A porous plastic bottle wrapped with filter paper fitted with two 2-mm diameter rubber tubes were installed in the pot at rhizosphere. Soil solution was collected from each bottle using $50 \mathrm{~mL}$ plastic syringe and carried to the laboratory and analyzed for K. Potassium was determined in the soil solution by flame photometer. Saturated soil samples were collected from each plastic pot inserting an auger like spatula up to root zone pressing by hand and kept into air tightly polythene bags. Collected soil samples were taken to the laboratory and analyzed. Exchangeable $\mathrm{K}$ was determined in the samples using neutral IN $\mathrm{NH}_{4} \mathrm{OAC}$ extraction method. Non-exchangeable $\mathrm{K}$ was also determined in the same samples using Modified Hunter and Pratt's method (1957). 


\section{Results and Discussion}

Soil solution K: Soil solution was collected at 15-day intervals from transplanting (0 DAT) to maturity (105 DAT). The collected soil solution samples were analyzed for $\mathrm{K}$. Soil solution $\mathrm{K}$ concentration was the highest at 0 DAT, decreased gradually and reached a steady state at 75 to 105 DAT (Fig. 1). Potassium concentration in soil solution gradually decreased with increasing growing period up to panicle initiation due to higher $\mathrm{K}$ uptake by rice (Yamakawa et al., 2004; Filep, 2002). Conducting field experiment at BAU farm in Boro and T. Aman seasons, Abedin Mian et al. (1991) and Afroz (2009) found that the concentration of $\mathrm{K}$ in soil solution increased with the increasing rate of $\mathrm{K}$ application but decreased with time. The $\mathrm{K}$ concentration was always the highest in Madhupur-2 soil followed by Madhupur-1 and the lowest in BAU-1 soil.
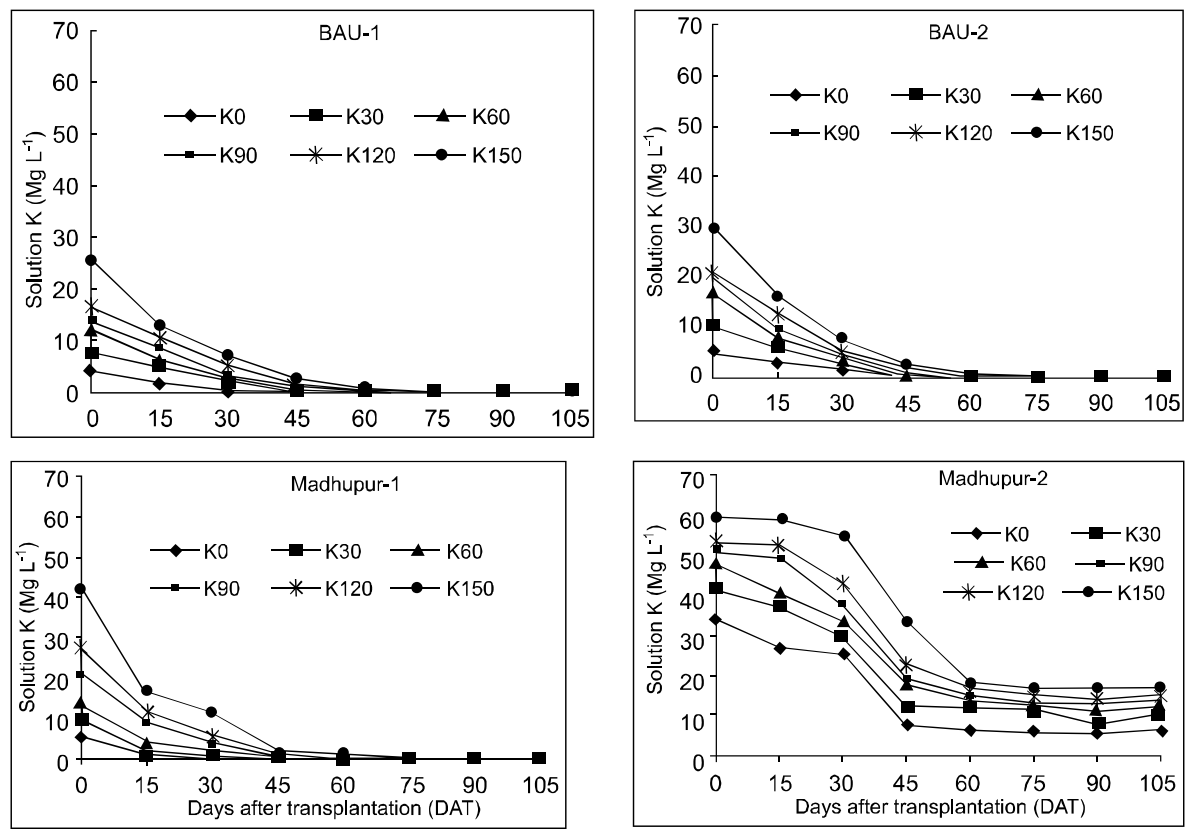

Fig. 1. Solution $\mathrm{K}$ in saturated soil under T. Aman rice culture

The initial soil solution $\mathrm{K}$ at 0 DAT was $4 \mathrm{mg} / \mathrm{L}$ in BAU-1 soil, $5 \mathrm{mg} / \mathrm{L}$ in BAU-2 soil, 6 mg/L in Madhupur-1 soil and $34 \mathrm{mg} / \mathrm{L}$ in Madhupur-2 soil. The concentration increased to 25, 30, 42, and $59 \mathrm{mg} / \mathrm{L}$ in BAU-1, BAU-2, Madhupur-l, and Madhupur-2 soils, respectively when $\mathrm{K}$ was applied to these soils. Soil solution K concentration decreased to $0.21 \mathrm{mg} / \mathrm{L}$ at $45 \mathrm{DAT}$ in $\mathrm{K} 0$ pot of BAU-1, BAU-2, and Madhupur-1 soils, while solution $\mathrm{K}$ reached this level at 60 DAT in $\mathrm{K}_{30}$ pot of BAU-l, BAU-2 and Madhupur-1 soils. At 75 DAT, the soil solutions $\mathrm{K}$ in the pots of BAU-1, BAU-2, and Madhupur-1 soils, 
receiving 60 to $150 \mathrm{~kg} \mathrm{~K} / \mathrm{ha}$ soil reached to $0.20 \mathrm{mg} / \mathrm{L}$. The Madhupur-2 soil showed a higher level of $\mathrm{K}$ in soil solution throughout the growing season. The $\mathrm{K}$ control pot of Madhupur-2 soil showed $27 \mathrm{mg} / \mathrm{L} \mathrm{K}$ at $15 \mathrm{DAT}$, which decreased to 6 to $8 \mathrm{mg} / \mathrm{L}$ during 60 to $105 \mathrm{DAT}$. Soil solution K concentration in $\mathrm{K}$ treated pots had 11 to $17 \mathrm{mg} / \mathrm{L}$ at $75 \mathrm{DAT}, 8$ to $17 \mathrm{mg} / \mathrm{L}$ at $90 \mathrm{DAT}$, and 7 to $14 \mathrm{mg} / \mathrm{L}$ at $105 \mathrm{DAT}$.

Exchangeable K: Results of exchangeable $\mathrm{K}^{+}$due to $\mathrm{K}$ application are presented in Fig. 2. The exchangeable $\mathrm{K}^{+}$ranged from 0.023 to $0.224,0.035$ to $0.280,0.037$ to 0.329 and 0.105 to $1.06 \mathrm{cmol} / \mathrm{kg}$ soil in BAU-1, BAU-2, Madhupur-1, and Madhupur-2, respectively, at 0 to $150 \mathrm{~kg} \mathrm{~K} / \mathrm{ha}$ application. The exchangeable $\mathrm{K}$ was the highest at $0 \mathrm{DAT}$ in all soils and then progressively decreased with the growing period of rice. Thippeswamy et al. (2000) reported that exchangeable $\mathrm{K}$ increased with increasing $\mathrm{K}$ doses up to $80 \mathrm{~kg} \mathrm{~K} / \mathrm{ha}$ and then decreased with growth stages of crop from tillering to harvesting. The exchangeable $\mathrm{K}$ at 0 DAT was the highest in Madhupur-2 soil and the lowest was in Madhupur-1 soil. At 0 DAT, the exchangeable $\mathrm{K}$ in $\mathrm{K}_{0}$ pot was 0.119, $0.134,0.084$, and $0.850 \mathrm{cmol} / \mathrm{kg}$ soil in BAU-1, BAU-2, Madhupur-1 and Madhupur-2 soils, respectively. Application of $\mathrm{K}$ fertilizer increased the exchangeable $\mathrm{K}^{+}$in all saturated soils at 0 DAT. Receiving $\mathrm{K}$ applications (150 $\mathrm{kg} / \mathrm{ha}$ ), exchangeable $\mathrm{K}$ increased to $0.224,0.281$, and $0.329 \mathrm{cmol} / \mathrm{kg}$ soil in BAU-1, BAU-2, Madhupur-l soils, respectively, and in K rich Madhupur-2 soil it increased to $1.06 \mathrm{emol} / \mathrm{kg}$ soil. The exchangeable $\mathrm{K}$ was drastically reduced to $0.035 \mathrm{cmol} / \mathrm{kg}$ soil at $60 \mathrm{DAT}$ in $\mathrm{K}_{0}$ pot of BAU-l soil, while this level reached in BAU-2 at 105 DAT. In Madhupur-l soil, the exchangeable $\mathrm{K}^{+}$drastically decreased in pot at 30 DAT. In Madhupur-2 soil, such reduction in exchangeable $\mathrm{K}^{+}$was also noted at $30 \mathrm{DAT}$. In all the 4 soils, the exchangeable $\mathrm{K}^{+}$in both treated and untreated pots progressively decreased at 75 DAT and maintained almost stable values between 90 and 105 DAT. The Madhupur-2 soil showed a higher level of $\mathrm{K}$ throughout the growing period of rice. The control pots of Madhupur-2 soil showed $0.853 \mathrm{cmol} / \mathrm{kg}$ soil, which decreased to 0.105 to $0.154 \mathrm{cmol} / \mathrm{kg}$ that was higher than that of other soils.

Non-exchangeable K: Changes in non-exchangeable K due to K application are shown in the Fig 3. In general, the amount of non-exchangeable $\mathrm{K}$ increased with the increasing incubation period irrespective of $\mathrm{K}$ levels up to 45 days and thereafter decreased up to 105 days. The highest amount of non-exchangeable $\mathrm{K}$ (3.49 me\%) was found in BAU-l soil compared to other soils due to presence of higher vermiculite (18\%) and the lowest value was exhibited in Madhupur-l soil due to absence of vermiculite (Table 1). Similar results were reported by (Singh and Moniker, 1976; Kansal and Sekhon, 1976; Talele et al., 1993). 

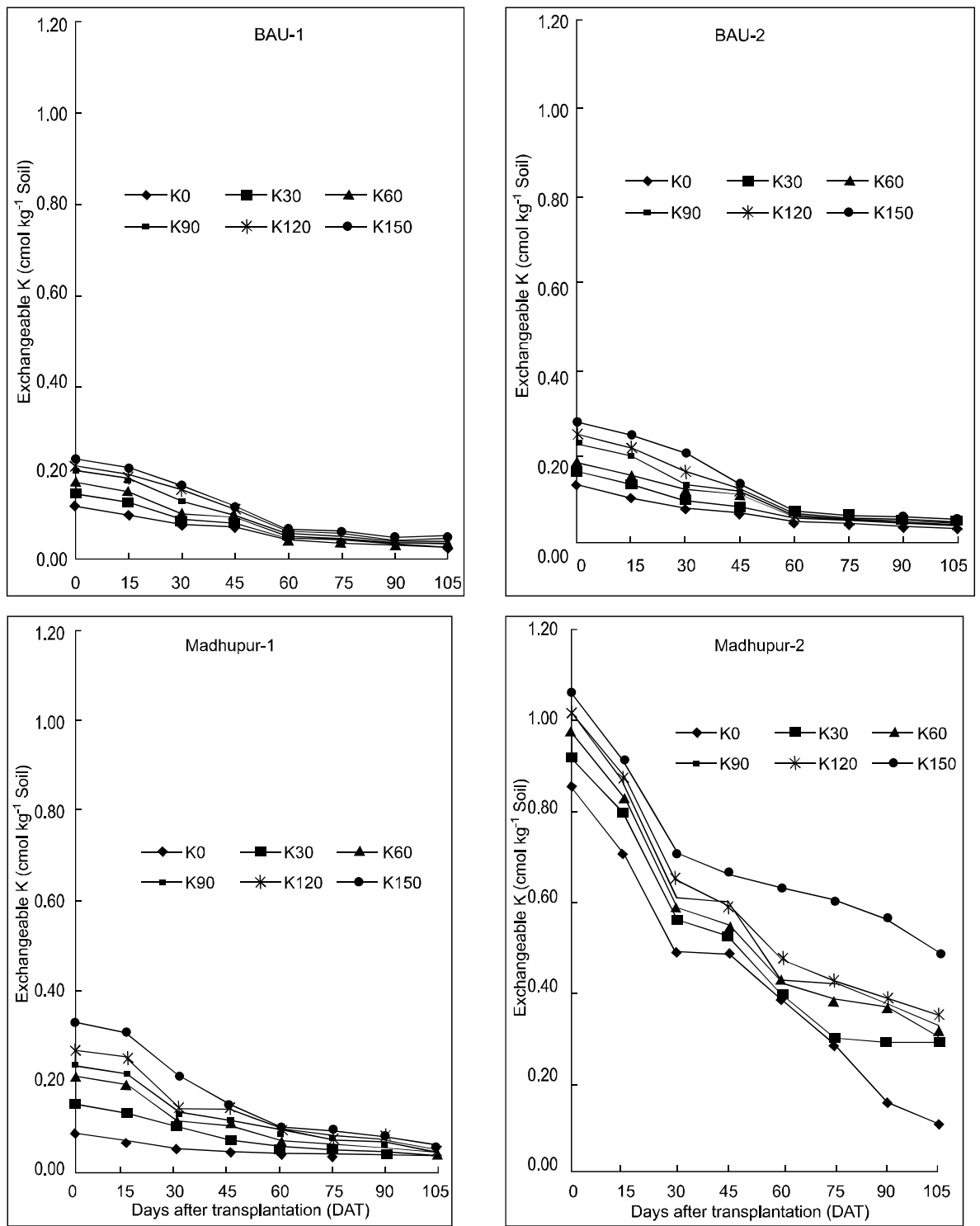

Fig. 2. Exchangeable K in saturated oil under T.Aman rice culture 

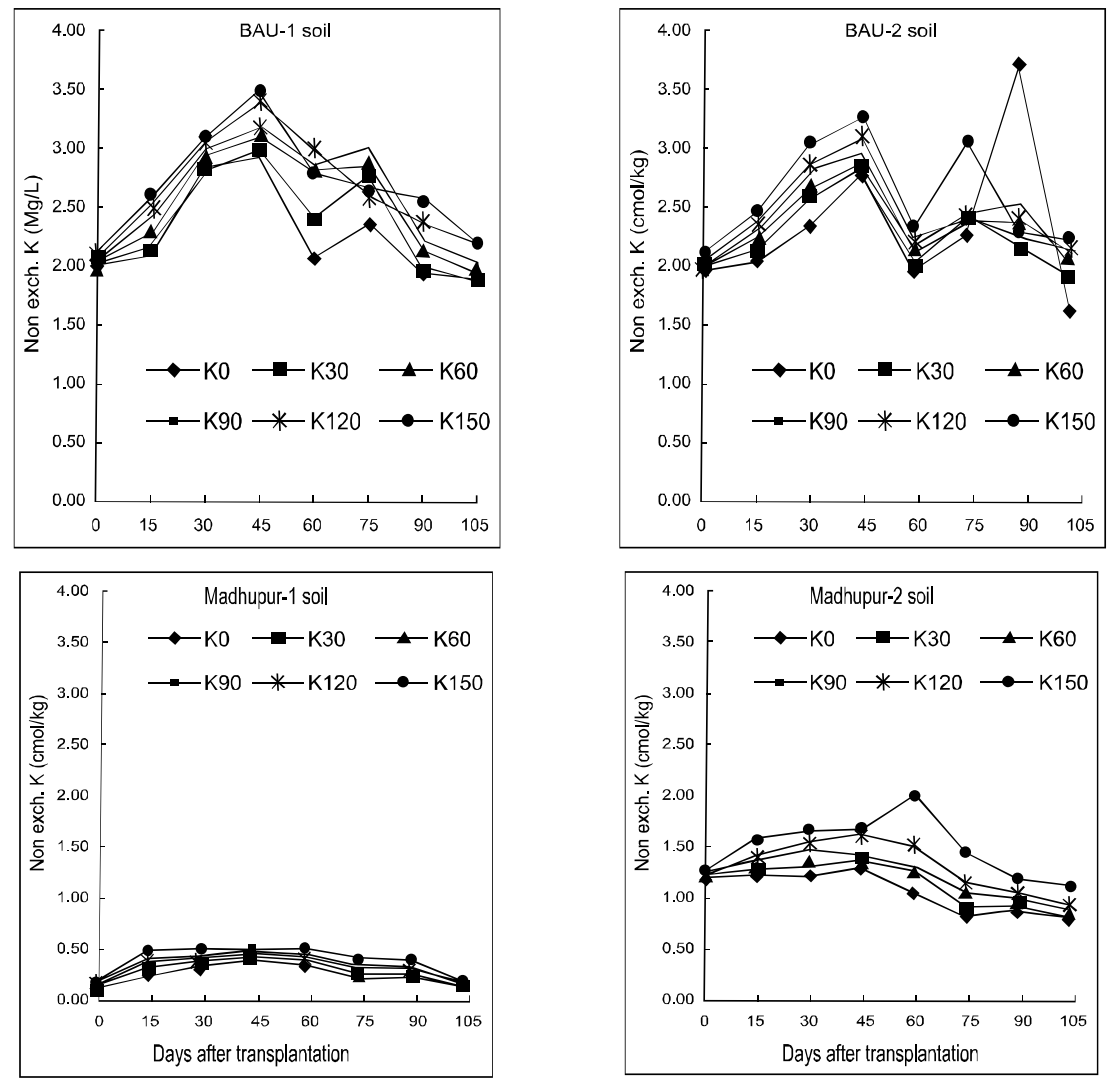

Fig. 3. Non-exchangeable $\mathrm{K}$ in saturated under T. Aman rice culture.

Table 1. Mineralogical properties of BAU and BADC farm soils (0-15 cm)

\begin{tabular}{l|l|l|l|l}
\hline \multirow{2}{*}{ Clay minerals (\%) } & \multicolumn{5}{c}{ Soils } \\
\cline { 2 - 5 } \multicolumn{1}{c}{ BAU-1 } & BAU-2 & Madhupur-l & Madhupur-2 \\
\hline Mica & 24.0 & 32.0 & 33.0 & 35.0 \\
Smectite & - & 1.0 & - & - \\
Vermiculite & 18.0 & 14.0 & - & 11.0 \\
Chloride & 17.0 & 26.0 & 6.0 & 8.0 \\
Kaolinite & 7.0 & 13.0 & 19.0 & 26.0 \\
Vermiculite- Chlorite & 18.0 & - & 7.0 & - \\
Vermiculite-Smectite & - & - & 26.0 & 7.0 \\
lnterstratified Mica-Chloride & 6.0 & 4.0 & - & - \\
Quartz & 3.0 & 5.0 & 7.0 & 9.0 \\
Goethite & 2.0 & 1.0 & 1.0 & - \\
Lepidocrocite & 4.0 & 1.0 & - & 1.0 \\
Feldspar & 1.0 & 3.0 & 1.0 & 3.0 \\
\hline
\end{tabular}




\section{Conclusion}

Soil solution $\mathrm{K}$ and exchangeable $\mathrm{K}$ increased with added $\mathrm{K}$. These forms of $\mathrm{K}$ decreased with time after crop transplantation and at 45 DAT drastic reduction was found. Thus, split application of K would give better result instead of single application. The amount of non- exchangeable K decreased inconsistently with time.

\section{References}

Abedin Mian, M.J., H.P. Blume, Z.H. Bhuiyan and M. Eaqub. 1991. Water and nutrient dynamics of a paddy soil of Bangladesh. Z. Planzenemähr. Bodenk. 154: 93-99.

Afroz, D., M.J. Abedin Mian, M.A. Hossain and E.S.M.H. Rashid. 2009. Effects of split application of potassium on yield and potassium balance for boro rice (BRRI dhan 29). Int. J. Bio. Res. 7: 73-79.

Beckett, P.H.T. 1964. The "immediate" Q/1 relations of labile potassium in the soil. $J$. Soil Sci. 19: 9-23.

Filep, T. 2002. Characterization of the nutrient buffering capacity of $\mathrm{K}, \mathrm{Ca}, \mathrm{Mg}$ in two Hungarian soils. Hungarian Contributions to the 17th International Congress of Soil Science, Bangkok, Thailand. 14-21 August 2002. Agrokemia-esPalajtan 51: 73-78.

Hunter, A. H. and P.F. Pratt. 1957. Extraction of potassium from soils by Sulphuric acid. Soil Sd. Amer. Proc. 21: 595-598.

Johnston, A. E. 1997. Understanding potassium and its use in agriculture. European Fertilizer Manufacturers Association, Belgium. 4: 1160.

Kansal, B. D. and G. S. Sekhon. 1976. Bull. J. Indian Soc. Soil Sci. 10: 78.

Singh, D. and N. D. Moniker. 1976. Bull. J. Indian Soc. Soil Sci. 10: 112.

Talele, P. E., G. K. Zende, Y. M. Patil, K. R. Sonar and B. D. Temboli. 1993. Effect of added $\mathrm{K}$ and incubation time on transformation of available $\mathrm{K}$ arid non-exchangeable K in different soils of Moharashtra. J. Indian Soc. Soil Sci. 41: 238-242.

Thippeswamy, H.M., B.G. Shivakumar and S.S. Balloli. 2000. Potassium transformation studies in lowland rice (O. sativa L.) as influenced by levels and time of $\mathrm{K}$ application. J. Potassium Res. 16: 7-11

Yamakawa Y., M. Saigusa, M. Okada and K. Kobayashi. 2004. Nutrient uptake by rice and soil solution composition under atmospheric $\mathrm{CO}_{2}$ enrichment. Plant Soil 259(12): 367-372. 